\title{
Anaesthetic management of vein of Galen malformation in a very low birth weight preterm baby for endovascular embolisation
}

\author{
Rajani MP Ramakrishnan, Shwetal U. Goraksha, Bhoomika P. Thakore, \\ Joseph N. Monteiro, Manju T. Butani
}

\begin{abstract}
Extra-cardiac arteriovenous malformations are rare causes of severe cardiac failure in the neonatal period.Aneurysmal malformation of the vein of Galen may lead to a diagnostic confusion because the presenting signs point to a cardiac cause of failure. Endovascular therapy is found to be an effective and safe therapeutic modality available to treat these lesions. Intervention in the newborn is difficult and is preferably postponed until about 5 months. We present the anaesthetic management of a very low birth weight preterm neonate with a vein of Galen malformation who needed intervention within the first week of life.
\end{abstract}

Key words: Endovascular embolisation, preterm, vein of Galen malformation

\section{INTRODUCTION}

Vein of Galen malformations (VOGMs) are rare anomalies of the intracranial circulation that constitutes $1 \%$ of all intracranial malformations. However, they represent $30 \%$ of vascular malformations presenting in the paediatric age group. ${ }^{[1,2]}$

The nomenclature is imprecise because the dilated venous structure that is characteristic of this malformation represents the embryonic median prosencephalic vein and not the vein of Galen itself. Patients usually present with neurological manifestations and can present with severe cardiac failure in the neonatal period.

P D N Hinduja Hospital and Medical Research Centre, Mumbai, Maharashtra, India

Address for correspondence:

Dr. Rajani Madathi Parambil Ramakrishnan, B54 RBI Officers

Quarters, Jalada, Tata Press Lane, Prabhadevi, Mumbai - 400 025,

Maharashtra, India.

E-mail: prajish.rajani1@gmail.com

\begin{tabular}{|l|l|}
\hline \multicolumn{2}{|c|}{ Access this article online } \\
\hline Quick Response Code: & Website: \\
\hline & www.jnaccjournal.org \\
\cline { 2 - 2 } & \\
\hline
\end{tabular}

Management of these lesions by definitive intervention is challenging, especially in the neonatal period.

Endovascular therapy has been found to be a safe and effective therapeutic modality to treat these lesions. Intervention in the newly born is difficult and is usually postponed until about 5 months of age, balancing the benefits of safe embolisation against the risk of cerebral damage. ${ }^{[3]}$

We report the anaesthesia management of a neonate with VOGM who needed emergency therapeutic intervention within the first week of life.

\section{CASE REPORT}

A preterm neonate delivered by caesarean section for foetal distress, with a very low birth weight of $1.75 \mathrm{~kg}$, developed respiratory and severe cardiac failure soon after birth. On systemic examination, the child

This is an open access article distributed under the terms of the Creative Commons Attribution-NonCommercial-ShareAlike 3.0 License, which allows others to remix, tweak, and build upon the work non-commercially, as long as the author is credited and the new creations are licensed under the identical terms.

For reprints contact: reprints@medknow.com

How to cite this article: Ramakrishnan RM, Goraksha SU, Thakore BP, Monteiro JN, Butani MT. Anaesthetic management of vein of Galen malformation in a very low birth weight preterm baby for endovascular embolisation. J Neuroanaesthesiol Crit Care 2016;3:137-40. 
had a hyperdynamic precordium with a pansystolic murmur in the mitral area and hepatomegaly. The blood investigations revealed a deranged coagulation profile with a raised activated partial thromboplastin time - 51.9 seconds. Serum electrolytes were $\mathrm{Na}-140$ $\mathrm{meq} / \mathrm{l}, \mathrm{K}-4.2 \mathrm{meq} / 1$ and the arterial blood gas showed $\mathrm{PH}-7.3, \mathrm{PCO}_{2}-43.5, \mathrm{PO}_{2}-70.5, \mathrm{HCO}_{3}-21.8$ on $\mathrm{FiO}_{2}$ 0.4. Two-dimensional echocardiography demonstrated severe pulmonary arterial hypertension with a ventricular septal defect with the right to left shunt. A prenatal ultrasonography had suggested a VOGM and a magnetic resonance angiogram confirmed a large VOGM directed towards the left [Figure 1].

Cardiac failure was treated with digoxin and enalapril. However, it was unsuccessful in controlling the high output failure. The Bicetre neonatal evaluation score was used to monitor progress daily. When the score dropped from 15 to 11 on day 4, an emergency endovascular embolisation was planned.

After confirming consent and adequate starvation, all standard monitors such as electrocardiography, $\mathrm{ETCO}_{2}$, pulse oximeter, non-ivasive blood pressure cuff and temperature probe were attached. Intra-operatively the heart rate was maintained at $120-130 / \mathrm{min}$, saturation was $98-99 \%, \mathrm{ETCO}_{2}$ at 30-32 mmHg and $\mathrm{PaCO}_{2}$ at 36-39 mmHg. Radiant warmers were used, and patient was adequately wrapped. The patient had a $24 \mathrm{G}$ intravenous catheter with a titrated dopamine infusion on flow. The child was induced with sevoflurane using JR-circuit and after confirming ventilation, muscle relaxant atracurium $0.5 \mathrm{mg} / \mathrm{kg}$ was given, and the patient was intubated with a $3.0 \mathrm{~mm}$ uncuffed endotracheal tube. Anaesthesia was maintained with sevoflurane, air: oxygen and fentanyl. The femoral artery was cannulated with a 5 French sheath and the sidearm of the sheath was transduced to monitor arterial pressure intra-operatively. The femoral vein was also

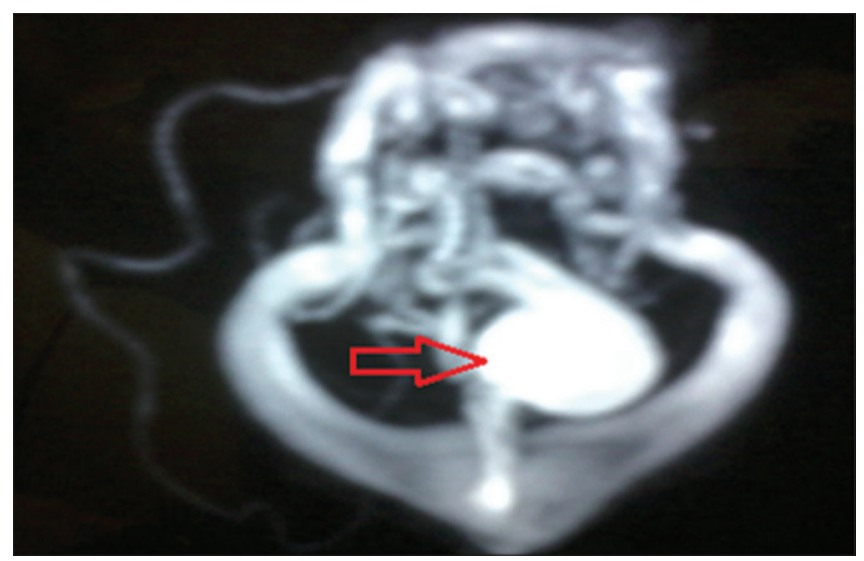

Figure 1: Magnetic resonance angiogram showing VGAM with tributaries secured. Since the patient was already on the inotropic support, we maintained normotension throughout the procedure. N-butyl-cyanoacrylate glue was used to embolise the feeding vessels - $60 \%$ obliteration was achieved [Figures 2-4].

The procedure lasted for $4 \mathrm{~h}$. The baby received crystalloids, $0.45 \%$ DNS with KCL, at $6 \mathrm{ml} / \mathrm{h}$ throughout the procedure. Since there was blood loss through the femoral sheath, we also gave a total of $30 \mathrm{ml}$ of packed red cells and $30 \mathrm{ml}$ of fresh frozen plasma to correct the loss. At the end of the procedure, the child had hypothermia and was shifted to the Neonatal Intensive Care Unit for elective ventilation and for further management. The baby's cardiac function improved almost immediately after the intervention. He started responding to the cardiac failure treatment. He was extubated on the $4^{\text {th }}$ day after the procedure. The baby also underwent an uneventful bilateral inguinal hernia repair 3 weeks later under general anaesthesia and was later discharged from the hospital a week after the surgery. After 6 months, a second stage embolisation was performed.

\section{DISCUSSION}

VOGMs are a rare and diverse group with a complex anatomy, pathophysiology and serious clinical sequelae.

VOGM is a misnomer. It is in fact the median vein of the prosencephalon, the embryonic precursor of the vein of Galen. These malformations are congenital vascular malformations made from multiple arterial feeders establishing direct or indirect shunts with large median vein collector. The latter is not the vein of Galen but a persistent embryonic channel that normally participates information of vein of Galen. ${ }^{[3,4]}$ This usually occurs between $6^{\text {th }}$ and $11^{\text {th }}$ week of intrauterine life..$^{[1,5]}$

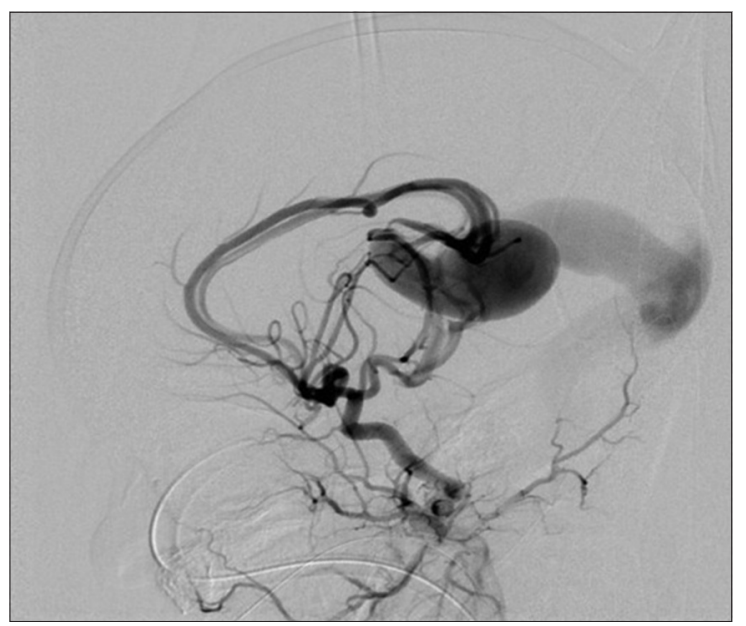

Figure 2: Angiographic view of vein of Galen malformation 


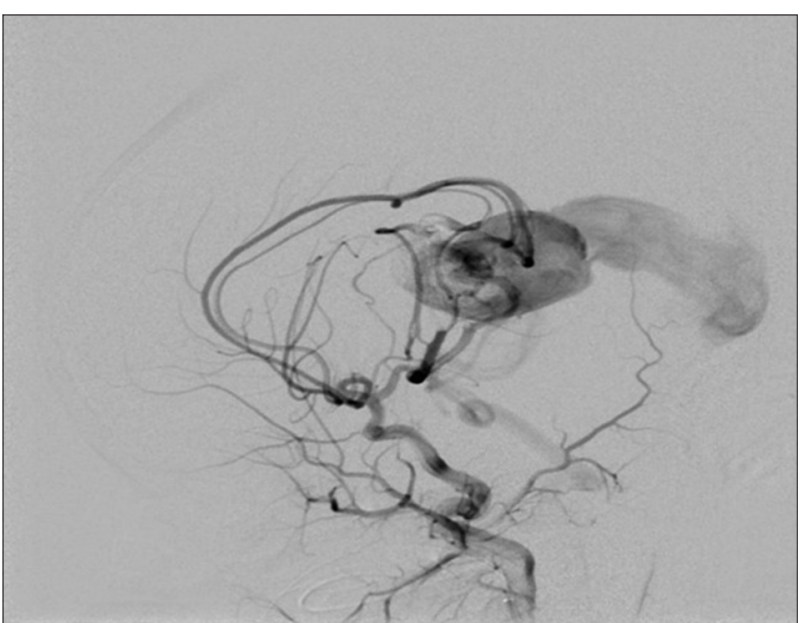

Figure 3: Decrease flow in feeding vessel after embolization

Patients present with cardiac and neurological manifestations depending upon the age of presentation. Neonatal manifestations can range from asymptomatic cardiomegaly to severe cardiac failure that is refractory to medical management. ${ }^{[6]}$ Infants and children usually present with macrocephaly or with hydrocephalus. Cardiac manifestations are absent or very mild. Patients with long-standing cerebral venous hypertension may present with delayed milestones. ${ }^{[1,7,8]}$ Older children and adults usually have low flow arteriovenous fistula. These patients present with a headache and seizures.

\section{Pathophysiology}

The cardiac manifestations are due to an increase in blood flow through the cerebral arteriovenous shunt. During intrauterine life, the low resistance of the placental circulation competes with the cerebral arteriovenous shunt and, therefore, the blood flow through the shunt is not as great as that after birth. ${ }^{[9]}$ After birth, exclusion of the low resistance placental circulation results in an abrupt increase in the flow across the cerebral arteriovenous fistula.

Neurological manifestations are due to cerebral venous hypertension.

Diagnosis is done with the help of imaging modalities. Prenatal ultrasound can detect VOGMs in the third trimester of pregnancy. ${ }^{[10-12]}$ Contrast-enhanced CT and magnetic resonance imaging are the modality of choice for an initial assessment to locate the fistulae. Cerebral angiography is the gold standard for the evaluation of the VOGMs.

Untreated VOGMs have a very poor prognosis. ${ }^{[1,13-15]}$ Endovascular therapy is the gold standard of the treatment, and surgical treatment is associated with high mortality. Stereotactic radiotherapy has a limited role. Aggressive medical management can help postpone therapeutic embolisation until the child is above

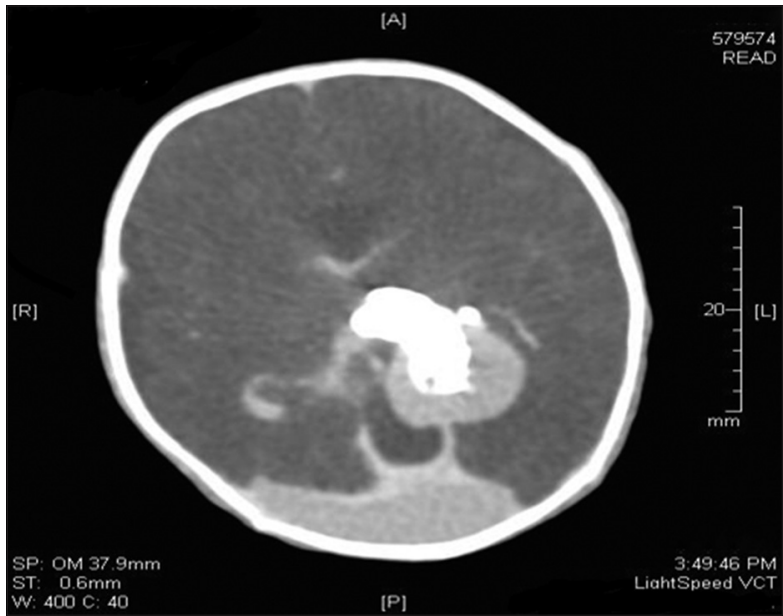

Figure 4: Computed tomography post-embolisation of VOGM

5-6 months of age at which point of time, intervention is easier and safer. Emergency embolisation of the malformation may be necessary to reduce the shunt in patients with congestive cardiac failure that is refractory to medical therapy. ${ }^{[1,7,14,15]}$

Lasjaunias et al. ${ }^{[3]}$ have described a 21 point Bicetre scale based on cardiac function, cerebral function, hepatic function, respiratory function and renal function. A score of $<8$ usually indicates poor prognosis and does not warrant emergency management. A Bicetre score of 8-12 is an indication for emergency management. A score of more than 12 indicates a well-preserved neonate and an attempt are made to delay the endovascular procedure by medical management.

The goal of therapy in cardiac failure patients is to arrest the congestive cardiac failure rather than to achieve complete obliteration of the shunt and then a later surgery can be performed in a staged manner to minimise the complications. Each session is limited by the volume of contrast agent delivered and how the patient tolerates the procedure. In non-cardiac failure patients, the goal is to prevent the consequences of chronic cerebral venous hypertension and promote normal cerebral development.

In our case as Bicetre score of neonate dropped from 15 to 11 emergency endovascular embolisation was planned. The anaesthetic challenges were neonatal anaesthesia, pathophysiology of the disease, remote location suite and radiation safety, haemodynamic manipulations and identifying and managing the complications.

The treatment of cardiac failure should be continued during the procedure. Both inhalational and intravenous agents can be used for induction: We used inhalation since the patient was on inotropic support. Despite potential adverse effects on intracranial compliance, ketamine is recommended for neonates in cardiac failure. 
Fluid management in these cases is challenging. Neonates cannot tolerate any fluid overload because of the cardiac failure; while on the other hand, children with contracted intravascular compartment from attempts at brain dehydration may experience sudden collapse following brisk perioperative bleeding. Moreover, there should be close watch kept over the volume of dye and intra-arterial flush used during the procedure, which can put an additional load on the neonate.

During a procedure with high flow shunts, controlled decrease in blood pressure may be required to slow flow in a feeding artery before injecting glue. However, a neonate with cardiac failure may not tolerate this and is, therefore, better avoided. Invasive intra-arterial monitoring is necessary for a patient in congestive cardiac failure undergoing neuroradioembolisation to keep a close watch on the haemodynamic stability.

Fatal complications that can occur during the procedure are intracranial haemorrhage and normal perfusion pressure breakthrough due to venous hypertension. This can be largely avoided by doing a staged embolisation and maintaining normotension in the post-operative period. ${ }^{[1,7]}$ Perforation of the venous sac has been reported to occur during the positioning of microcatheter and can be managed by reversal of anticoagulation and continuation of embolisation. Ischemic neurological deficits can be occasionally encountered after embolisation. Pulmonary embolisation with an embolic agent is common considering the high flow across the intracranial shunts.

Post-operatively, these patients are ventilated and sedated to maintain haemodynamic and respiratory stability. Hypertension is avoided in $1^{\text {st }} 48 \mathrm{~h}$ after the procedure to prevent neurological hyperperfusion syndrome.

\section{CONCLUSION}

Management of intra-cerebral arteriovenous fistulae in the newborn is difficult. It needs to be individualised depending on the clinical parameters and the expected outcome. The Bicetre score is a useful guide to management and timely intervention. It is essential to maintain haemodynamic stability to ensure adequate cerebral perfusion pressure during the endovascular embolisation. A multidisciplinary approach involving the neonatologist, cardiologist, neuroanaesthesiologist and the interventional neuroradiologist is required to achieve a good outcome as the morbidity and mortality still remains high in the newborn period.

\section{Financial support and sponsorship}

Nil.

\section{Conflicts of interest}

There are no conflicts of interest.

\section{REFERENCES}

1. Gupta AK, Varma DR. Vein of Galen malformations: Review. Neurol India 2004;52:43-53.

2. Casasco A, Lylyk P, Hodes JE, Kohan G, Aymard A, Merland JJ. Percutaneous transvenous catheterization and embolization of vein of Galen aneurysms. Neurosurgery 1991;28:260-6.

3. Lasajunias PL, Chng SM. The management of vein of Galen aneurysmal malformations. Neurosurgery 2006;59:53-184.

4. Yasargil MG. Microneurosurgery IIIB. New York: Thieme Medical Publishers; 1988. p. 323-57.

5. Raybaud CA, Strother CM, Hald JK. Aneurysms of the vein of Galen: Embryonic considerations and anatomical features relating to the pathogenesis of the malformation. Neuroradiology 1989;31:109-28.

6. Kothari SS, Naik N, Juneja R, Saxena A. Aneurysm of the vein of Galen in neonates: Report of four cases. Indian Heart J 2001;53:499-502.

7. Berenstein A, Lasjaunias P. Arteriovenous fistulas of the brain. In: Surgical Neuroangiography 4. Endovascular Treatment of Cerebral Lesions. Berlin: Springer-Verlag; 1992. p. 267-317.

8. Lasjaunias P, Terbrugge K, Piske R, Lopez Ibor L, Manelfe C. Dilatation of the vein of Galen. Anatomoclinical forms and endovascular treatment apropos of 14 cases explored and/or treated between 1983 and 1986. Neurochirurgie 1987;33:315-33.

9. Hoffman HJ. Malformations of the vein of Galen. In: Edwards MS, Hoffmann HJ, editors. Current Neurosurgical Practice: Cerebral Vascular Disease in Children and Adolescents. Baltimore: Williams and Wilkins; 1989. p. 239-46.

10. Mendelsohn DB,Hertzanu Y,Butterworth A.Inuterodiagnosis of a vein of Galen aneurysm by ultrasound. Neuroradiology 1984;26:417-8.

11. Reiter AA, Huhta JC, Carpenter RJ Jr, Segall GK, Hawkins EP. Prenatal diagnosis of arteriovenous malformation of the vein of Galen. J Clin Ultrasound 1986;14:623-8.

12. Hirsch JH, Cyr D, Eberhardt H, Zunkel D. Ultrasonographic diagnosis of an aneurysm of the vein of Galen in utero by duplex scanning. J Ultrasound Med 1983;2:231-3.

13. Casasco A, Lylyk P, Hodes JE, Kohan G, Aymard A, Merland JJ. Percutaneous transvenous catheterization and embolization of vein of Galen aneurysms. Neurosurgery 1991;28:260-6.

14. Johnston IH, Whittle IR, Besser M, Morgan MK. Vein of Galen malformation: Diagnosis and management. Neurosurgery 1987;20:747-58.

15. Lasajunias PL, Chng SM. The management of Vein of Galen aneurysmal malformations. Neurosurgery 2006;59:53-184. 